\title{
Mesenchymal stem cell mediates cardiac repair through autocrine, paracrine and endocrine axes
}

\author{
Celia Sid-Otmane ${ }^{1,3} \mathbb{D}$, Louis P. Perrault ${ }^{1,3,4}$ and Hung Q. Ly ${ }^{1,2,3^{*}}$
}

\begin{abstract}
In the past decade, despite key advances in therapeutic strategies following myocardial infarction, none can directly address the loss of cardiomyocytes following ischemic injury. Cardiac cell-based therapy is at the cornerstone of regenerative medicine that has shown potential for tissue repair. Mesenchymal stem cells (MSC) represent a strong candidate to heal the infarcted myocardium. While differentiation potential has been described as a possible avenue for MSC-based repair, their secreted mediators are responsible for the majority of the ascribed prohealing effects. MSC can either promote their own survival and proliferation through autocrine effect or secrete trophic factors that will act on adjacent cells through a paracrine effect. Prior studies have also documented beneficial effects even when MSCs were remotely delivered, much akin to an endocrine mechanism. This review aims to distinguish the paracrine activity of MSCs from an endocrine-like effect, where remotely transplanted cells can promote healing of the injured myocardium.
\end{abstract}

Keywords: Paracrine, Autocrine, Endocrine, Mesenchymal stem cells, Remote delivery

\section{Background}

Ischemic heart disease (IHD) due to coronary artery disease remains a serious burden on health systems across Western countries. Medical advances and device-based therapies have impacted mortality and improved quality of life of such patients [1]. These therapies are designed to rescue the ischemic but viable tissue only and fail to address the key molecular targets participating in the pathological cardiac remodeling [2]. Cardiomyocytes being terminally differentiated with minimal regenerative ability $(0.5-2 \%)$, cardiac transplantation remains the only true cure for failing hearts [3]. However, the limited number of available donors limits the impact of such a therapeutic avenue. Tissue regeneration has emerged as a

*Correspondence: qh.ly@umontreal.ca

${ }^{3}$ Research Centre, Montreal Heart Institute, Université de Montréal, 5000 Belanger Street, Montreal, QC H1T 1C8, Canada

Full list of author information is available at the end of the article promising field of research using mainly cell-based therapy [4].

Embryonic and adult stem cells are capable of generating new tissue through differentiation into multiple lineages. Embryonic stem cells (ESC) isolated from the inner cell mass of blastocytes are pluripotent and capable of generating the three germinal layers [5]. However ethical issues and teratoma formation limit their clinical use. Induced pluripotent stem cells (iPSC) have very similar characteristics to ESC where terminally differentiated cells have been used to generate pluripotent cells [6]. Clinical translation of iPSC overcomes ethical issues related to ESC but security concerns with teratoma formation hinder their clinical use [7].

Of the adult stem cells, MSCs represent an interesting population that garnered increased interest for clinical translation in the past decade. First identified and isolated from bone marrow, stromal stem cells have now been isolated from various organs such as placenta, cord blood or adipose tissue [8]. When isolated from adipose 
tissue, they are called adipose derived stem/stromal cells (ASCs) and have become attractive candidates for cellbased therapy as they are readily and more easily isolated while engendering minor donor discomfort, compared to their bone marrow derived counterparts. Furthermore, adipose tissue offers higher quantities of stem cells compared to bone marrow [9]. At first, the self-renewal and differentiation of stromal stem cells were the main reasons for their use in regenerative medicine. Moreover, their low immunogenicity and documented immunomodulatory properties [10] prompted the possibility to have a bank of cells available for allogenic transplantation for "off the shelf" use in various clinical conditions. The major limitation in their therapeutic efficacy however has been their low engraftment after transplantation [11]. Nevertheless, in the last decade, conflicting results on engraftment percentage prompted a debate as to whether engraftment was mandatory to the therapeutic efficiency. It is very unlikely that the low engrafted rate of cells explains the reported therapeutic impact in both preclinical and clinical studies [12]. The trophic and immunomodulatory properties of MSCs are now believed to be the main mechanism underpinning the therapeutic impact in preclinical studies [13]. Unfortunately, there remains discrepancies between animal models and clinical studies that hamper the transition from bench to bedside. Unraveling key modulators in the secretome will promote successful clinical transition.

In order to heal after an ischemic episode, different processes need to act in concert (Fig. 1). Cardiac cell-based therapy can either act directly through transdifferentiation and fusion to replenish the lost tissue or indirectly by promoting angiogenesis, immunoregulation and inhibiting apoptosis and fibrosis through released factors [14]. Various clinical trials have been conducted using MSCs or ASCs in cardiovascular disease. Studies have examined both autologous and allogeneic cell transplantation (summarized in Table 1). The POSEIDON study concluded on comparable safety and efficacy between allogeneic and autologous MSCs [15]. The PRECISE study was the first randomized placebo-controlled trial showing feasibility and safety of transendocardial administration of ASCs [16]. Adverse effects have been rarely reported and cells showed some efficacy in improving cardiac function. However, better knowledge of parameters such as delivery route, cell dosage and appropriate timing for administration can substantially improve effectiveness [17]. Rushing translation to clinical application despite poor understanding of the biological mechanisms have yielded heterogenous efficacy outcomes. Investigating the kinetics of cell or derived components delivery is still a challenge. There is a lack in defining the best scenario between early and late administration, balancing between

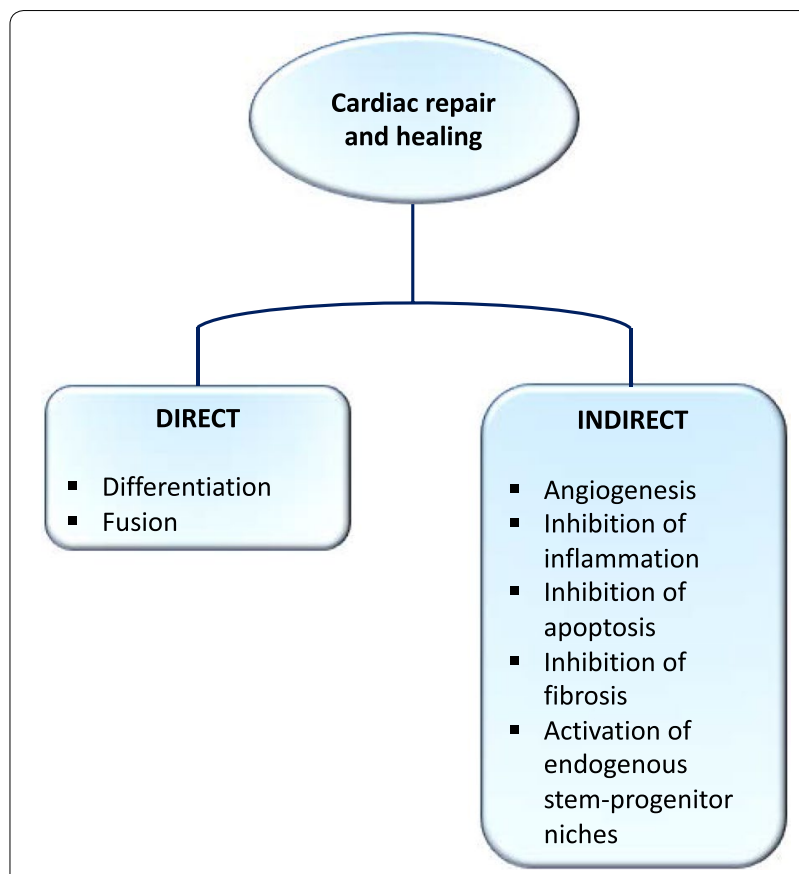

Fig. 1 Cardiac healing and repair mediated by direct and indirect mechanisms in cardiac cell therapy

risk of toxic microenvironment for the injected material early-on after reperfusion or massive tissue damage because of delayed administration. From clinical studies, it was demonstrated that the most efficient time window for treating myocardial infarction is within a week after reperfusion [18]. More trials should follow this lead in order to confirm this time window.

\section{Adipose tissue derived stem/stromal cells}

ASCs were first discovered after their isolation from processed lipoaspirate by Zuk et al. in 2001 [19]. ASCs share many properties with bone-marrow MSC including their tri-lineage differentiation and the production of a variety of mediators. ASCs contribute directly to the homeostasis, tissue reparation and cell renewal in the adipose tissue. The International Fat Applied Society reached a consensus in 2013 regarding the minimum phenotypic criteria to characterize ASCs as CD39+, CD73+, CD44+, CD105+, CD90+, CD45-, CD31- plastic adherent stem/stromal cells. The expression of certain surface markers such as CD34 may change throughout cell division, meaning that different subpopulations of ASCs may exist in vivo [20]. They secrete factors that may inducing angiogenic and anti-apoptotic effects along with immunomodulatory properties. Therapeutic use of ASCs has thus far been promising in translational studies with encouraging data regarding safety and feasibility in clinical trials [21]. The interest in ASCs rests less on 
Table 1 Clinical benefits from key clinical trials using stromal stem cells in heart diseases

\begin{tabular}{|c|c|c|c|c|c|c|c|}
\hline Clinical trial & Year & Cell type & Patient population & Delivery route & LVEF & LVEDV & Infarct size \\
\hline POSEIDON [15] & 2012 & $\begin{array}{l}\text { Allogeneic and autolo- } \\
\text { gous BM-MSC }\end{array}$ & $\begin{array}{l}\text { ICM } \\
\text { LVEF } \leq 50 \%\end{array}$ & Transendocardial & $\uparrow$ & $\downarrow$ & $\downarrow$ \\
\hline APOLLO [66] & 2012 & Autologous ASC & STEMI & Intracoronary & $\leftrightarrow$ & N/A & $\downarrow$ \\
\hline C-CURE [67] & 2013 & Autologous BM-MSC & LVEF 15-40\% & Endoventricular & $\uparrow$ & $\downarrow$ & N/A \\
\hline PROMETHEUS [68] & 2014 & Autologous BM-MSC & ICM & Intramyocardial & $\uparrow$ & $\downarrow$ & $\downarrow$ \\
\hline PRECISE [16] & 2014 & Autologous ASC & ICM, CABG & Transendocardial & $\leftrightarrow$ & $\leftrightarrow$ & $\leftrightarrow$ \\
\hline Gao et al. [69] & 2015 & Allogeneic WJ-MSC & STEMI & Intracoronary & $\uparrow$ & $\downarrow$ & N/A \\
\hline TRIDENT [70] & 2017 & Allogeneic BM-MSC & ICM, LVEF $\leq 50 \%$ & Transendocardial & $\leftrightarrow$ & $\leftrightarrow$ & $\downarrow$ \\
\hline CHART-1 [71] & 2017 & Autologous BM-MSC & $I H F, L V E F \leq 35 \%$ & Intramyocardial & $\leftrightarrow$ & $\leftrightarrow$ & N/A \\
\hline ATHENA [72] & 2017 & Autologous ASC & $\begin{array}{l}I C M \\
20 \% \leq L V E F \leq 45 \%\end{array}$ & Intramyocardial & $\leftrightarrow$ & $\leftrightarrow$ & N/A \\
\hline MyStromalCell [73] & 2017 & Autologous ASC & $\begin{array}{l}\text { ICM } \\
\text { LVEF }>40 \%\end{array}$ & Intramyocardial & N/A & N/A & N/A \\
\hline
\end{tabular}

$\leftrightarrow \uparrow \downarrow$ Respectively mean no change, increase and decrease. N/A means not measured

$B M$ Bone marrow, WJ Wharton Jelly, ICM ischemic cardiomyopathy, CABG Coronary Artery Bypass Grafting, LVEF Left Ventricular. Ejection Fraction, LVEDV Left Ventricular End-Diastolic Volume, ICM Ischemic Cardiomyopathy, STEMI ST-elevation Myocardial Infarction

their differentiation capacity but rather on their ability to modulate their microenvironment by affecting injured cells through the release of a plethora of mediators.

\section{Direct mechanisms for cardiac repair: differentiation and fusion}

The differentiation of MSCs/ASCs into cardiomyocytes, endothelial cells and vascular smooth muscle cells, the three main components of the cardiovascular system, have been previously been reported as achievable [22]. More specifically, in vivo differentiation of ASCs into cardiomyocytes has been documented since its first description [23]. After 3 weeks of treatment with 5-Azacytidine, cells showed spontaneous beating when observed under phase contrast microscope. Full phenotype characterisation showed positive staining for myosin heavy chain, $\alpha$-actinin and troponin I. The differentiation was maintained up to 2 months. Cardiomyogenesis was also shown on ASCs spontaneously, with a pacemaker activity documented in electrophysiological studies on early ASC culture. Nevertheless, 5-Azacytidine induced cardiomyogenic differentiation remains controversial as such findings were not reproducible. Key cardiac marker expression such as cardiac troponin I and $\mathrm{T}$ and sarcomeric $\alpha$-actinin as well as cardiac transcription factors GATA4 and Nkx2,5 were not detected [24].

Several studies have demonstrated in vivo engraftment and further differentiation into cardiomyocytes and endothelial cells after myocardial infarction (MI) $[25,26]$. Yoon et al. reported engraftment and transdifferentiation of intramyocardially transplanted MSCs into cardiomyocytes [27]. Moreover, Valina et al. compared the intracoronary infusion of both BM-MSCs and ASCs on a porcine acute myocardial infarction (AMI) model. The group described similar efficacy of ASCs and BM-MSCs on cardiac function and angiogenesis but ASCs had better impact on LV remodelling [28]. This study also showed cell engraftment 4 weeks after transplantation with expression of endothelial cell markers CD31 and vWF in the engrafted cells. Fusion and mitochondrial transfer might also be another mechanism to cardiomyogenesis following ASCs transplantation [29]. One study showed in a murine AMI model, fusion of ASCs with cardiomyocytes with expression of connexin 43 and troponin I [30]. However, an important percentage of transplanted cells were lost through apoptosis or other mechanisms due to the harsh microenvironment in the infarcted area. Subsequently, it was also reported that a mild percentage of engraftment occurred without differentiation into cardiomyocytes, endothelial cells or smooth muscle cells [31]. Thus, it is unlikely that the transdifferentiation or cellular fusion of the low level of engrafted cells could account for the improved cardiac function after stem cell delivery.

\section{Autocrine effects}

The autocrine activity of MSCs is induced by secreted factors acting on the stem cell itself. The majority of studies exploring the autocrine effects of MSCs are related to their differentiation capacity [32,33]. Mediators in the conditioned media influenced differentiation capacity of MSCs or ASCs through an autocrine loop [34, 35]. For example, an autocrine signalling activity of VEGF-A was shown to influence osteogenic differentiation of human MSCs [36]. Another group demonstrated the importance of released FGF-2 and HGF on stemness of MSCs [37]. In addition, autocrine regulation has been described to 
influence immunomodulator mediators release. Stimulation of TLR3 on MSCs, which produced high levels of IL-6 and IL-8, upregulated TLR3 expression, hence inducing a positive feedback loop on IL-6 and IL-8 secretion [38]. Furthermore, autocrine effects can enhance survival or proliferation of stem cells in a hostile microenvironment. Lee et al. proved that PGE-2 secreted by human umbilical cord blood MSCs and ASCs plays a major role in maintenance of their self-renewal through EP2 receptor [39].

\section{Paracrine effects}

It is now widely accepted that the main benefits of MSC therapy are derived from the effects of secreted factors acting on neighboring cells through a paracrine phenomenon. The diversity in the secreted factors constituting the secretome has been described and key factors have been identified such as VEGF, HGF, IGF-1, SDF1 $\alpha$, TGF- $\beta$ and TSG- 6 [40-42]. These mediators stimulate angiogenesis, inhibit apoptosis or modulate inflammatory pathways. Intramyocardial or intracoronary administration of stem cells are the routes for direct delivery that can permit paracrine effects on the injured myocardium. Bobi et al. used a porcine model of AMI and demonstrated increased gene expression of SDF-1 $\alpha$, GMCSF and VEGF early on after intracoronary ASC injection. Enhancement of neovascularization is one of the most important therapeutic approaches needed to limit complications from post ischemic injury. Pro-angiogenic, antiapoptotic and anti-inflammatory effects have been described in this study [43]. Unfortunately, clinical studies used intracoronary administration of MSCs in acute myocardial infarction with contradictory findings, some showing improvements while others failed to report significant effects on either cardiac function or remodeling [44-46]. Intracoronary infusion has been preferred for the specificity of cell delivery to the target area. Caution has been raised regarding use of this route of delivery which might be associated with microvascular embolization leading to no-reflow phenomena. Nonetheless, recent clinical trials recognized safety of intracoronary injection of up to 50 millions of large size stem cells if injected a few days after myocardial infarction $[47,48]$.

Intramyocardial delivery has been associated with limited cell retention and engraftment. However, whether injected in the infarcted area or in the peri-infarcted zone, intramyocardial delivery of MSCs was able to ameliorate the infarct size. Perin et al. reported improved left ventricular ejection fraction (LVEF) and enhanced capillary density with transendocardial injection of allogenic MSCs in a canine AMI model [49]. However, Rigol et al. found that intracoronary infusion of ASCs improved neovascularization in porcine MI model compared to transendocardial demonstrating some conflicting results [26].

Yang et al. also concluded that the cardioprotective effect attributable to ASCs was mainly due to paracrine effects. They compared human ASCs vs. ASC-conditioned medium in a mice model of $\mathrm{MI}$ and observed a reduced infarct size, reduced cardiomyocyte apoptosis and improved cardiac function by both treatments. These results illustrated the sufficient impact of a cocktail of mediators injected in the peri-infarcted area [50].

Extracellular vesicles (EVs) are now recognized as important intercellular messengers involved in transmission of biological signals including proteins, lipids and RNAs. Exosomes are one subgroup of EVs originating from the fusion of multivesicular bodies and plasma membrane of stem cells and are retrieved in the secretome of MSCs of different origins. They are particularly enriched with mRNAs or micro RNAs (miRNAs) and have been investigated in acute kidney injury and ischemic disease such as stroke and myocardial ischemia reperfusion injury [51]. Some groups have experimented direct myocardial injection of MSC derived exosomes and observed reduced infarct size, preserved systolic/ diastolic function and enhanced angiogenesis in a rat model of MI [52, 53]. Based on some reports, MSCderived exosomes are accountable for the cardioprotective effects as their depletion from the conditioned media suppressed this protection [53]. This statement implies minor impact of cytokines and factors in the conditioned media of MSCs. It is presumed that exosomes are less prone to enzymatic degradation than the abovementioned factors. The exact components of the cargo of exosomes that provide cardioprotection are yet to be discovered and characterized. It is fundamental to investigate efficacy difference between injecting conditioned media or MSCs, knowing that the advantage of cell injection is the responsiveness to the specific microenvironment whereas secretome can't anticipate the pathological environment. It is even more complex knowing that some groups have demonstrated that not all exosomes are equivalent in their therapeutic impact $[54,55]$.

Endogenous cardiac progenitor cells in the myocardium are likely able to differentiate into cardiomyocytes, endothelial cells or smooth muscle cells to contribute to cardioprotection once activated. Given that their isolation and expansion is complex and still needs optimization for clinical application, stimulation and activation of endogenous progenitor cells by MSC secretome represents an advantage that can be exploited by cardiac cell therapy. Findings from in vitro and in vivo experiments have alluded to augmented differentiation and proliferation of cardiac progenitor cells through paracrine effects of MSCs [56, 57]. Release of SDF- $1 \alpha$ and VEGF from 
transplanted MSCs and myocardial tissue was responsible for $\mathrm{c}^{-\mathrm{kit}^{+}}$cell mobilization from the heart itself and from bone marrow to the infarcted region [57].

\section{Endocrine-like effects}

An endocrine organ secretes hormones and factors that act at distance on other tissues. Factors need to circulate systemically to reach their specific receptors in order to intervene in their endocrine feedback loop. Aside from intracoronary and intramyocardial injections of MSCs discussed above, another route of delivery that has been tested in clinical trials is the intravenous injection, which is associated with ease of use and clinical translation. The pulmonary first pass effect has limited the number of cells reaching the infarcted myocardium when injected intravenously. Homing to the damaged tissue is then limited by entrapment in microvasculature when using this systemic administration [58]. Despite this seemingly disadvantageous side effect, Lee et al. have reported that entrapped MSCs in the lungs vasculature can induce therapeutic effects on the myocardium, reducing infarct size and improving cardiac function. These effects were attributed to various secreted factors but mainly TSG-6 [42]. This report remains a key finding hinting to an endocrine-like effect induced by secreted factors following cardiac cell therapy.

Intramuscular administration of stem cells is another remote delivery method that has been investigated for cardiac repair. In a rat dilated cardiomyopathy model, an intramuscular injection of human umbilical cord derived stem cells significantly elevated LVEF and left ventricular fraction shortening. Levels of circulating HGF, LIF, GMCSF and VEGF were increased as well as the myocardial expression of HGF, IGF-1 and VEGF without stem cell homing to myocardium. Moreover, intramuscular injection into skeletal muscle did not induce any inflammation or ulceration in the tissue [59]. Intramuscularly administered MSC are largely trapped in the musculature without any detectable migration. A further advantage to the use of skeletal muscle as a repository for cell delivery is the ability to perform more than one injection without increased risk compared to more invasive methods. Remote delivery of MSCs into hind limb skeletal muscle has been found to improve ventricular function in a hamster heart failure model [60]. Elevated levels of HGF, LIF and G/M CSF as well as increased circulating c-kit cells, CD31+ cells and CD133+ cells were detected. Investigators considered the existence of a crosstalk between injected MSCs and endogenous bone marrow cells that would elicit increased activation of cardiac c-kit cells, involved in the cardiac repair. This crosstalk describes the dynamic and functionally relevant signalling pathways involved in the stem cell cardiac repair. Activated cardiac progenitor cells can further stimulate myocardial expression of paracrine factors.

Although subcutaneous MSC administration has been widely used in wound repair studies, its use in cardiac disease remains unexplored. Preda et al. hypothesized that a remote transplantation of ASCs transfected with heme oxygenase 1 could protect the heart from ischemia reperfusion injury. They reported that subcutaneously injected ASCs did not migrate systemically yet proliferated locally at the injection site. These genetically modified ASCs were able to improve cardiac functions post infarct despite their remote location from the site of injury [61]. Thus, Pentraxin 3 was identified as a possible mediator, acting in an endocrine-like manner to enact cardioprotection against ischemia reperfusion injury.

Human pharmacokinetic of biologic drugs is predictable when injected intravenously but this remains less clear regarding subcutaneous injections. Understanding the biodistribution and absorption of drugs delivered subcutaneously remains complex because of challenges to correlate preclinical findings in clinical setting due to the inherent difference in the subcutaneous tissue between humans and other species. Prediction of human pharmacokinetics following subcutaneous injection would rely on mechanistic studies rather than empirical scales. The implication of the lymphatic system in this route of delivery is also important. Blood capillaries are tight in their endothelial junctions, the transfer of macromolecules is then facilitated in the lymphatic capillaries as they have incomplete basal lamina which enables drainage of interstitial macromolecules without size restriction [62].

Exosomes as well as other trophic factors are the main actors of the immunoregulatory effect provided by MSCs. The main elucidated mechanisms in immunoregulation involve indoleamine 2,3-deoxygenase (IDO) or inducible nitric oxide synthase (iNOS), depending on the source of MSCs. IDO is an enzyme that catabolizes tryptophan and iNOS produces $\mathrm{NO}$ and both mediators can inhibit $\mathrm{T}$ cells [10]. Genetic knockdowns of these enzymes proved their implication in the immunosuppression, but the exact mechanisms are still unclear. Some direct interaction between MSCs and immune cells can also occur. Expressed factors on MSCs such as the co-stimulatory factors PDL1 and FASL can inhibit activated $\mathrm{T}$ cells by binding to CD80 [63].

The remote impact of MSCs on cardiac repair could be mediated by the activation of pericytes, microvascular mural cells. Pericytes are characterized by a strong regenerative ability, closely resembling MSC. Stem cell therapy has demonstrated that pericyte injection can reverse cardiac remodelling inhibiting fibrosis and inflammation while promoting angiogenesis [64]. One 


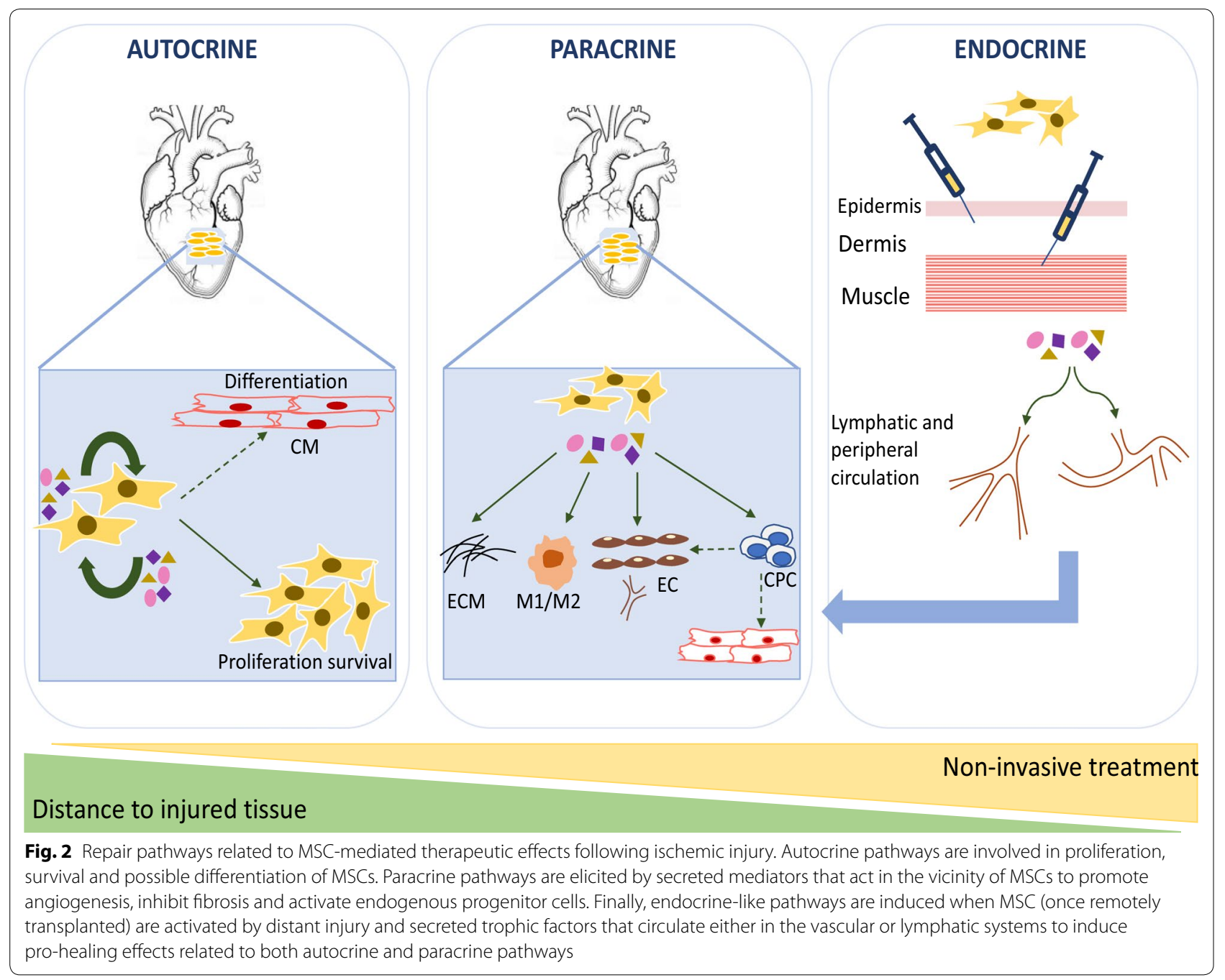

could hypothesize a crosslink between injected MSCs and resident pericytes that can potentiate the pro-healing impact of the cell transplantation. The involvement of pericytes could be their contribution to the pro-angiogenic effect of ASCs as the essential function of pericytes is to recruit and stabilize endothelial cells.

Finally, pericytes are also likely to participate in the regulation of the recruitment of immune cells following myocardial infarction, a role that has been described in other tissues [65]. Demonstrating efficiency of remote cell-based therapy would allow for non-invasive methods to treat ischemic heart disease. With the plethora of factors released following remote cell delivery, stem cells mobilized from niches such as bone marrow or activated endogenous cardiac progenitors can initiate and induce cardiac repair and/or regeneration following ischemic injury.

\section{Conclusion}

The therapeutic potential of MSCs/ASCs can be exerted through different mechanisms involving autocrine activity to enhance stemness, paracrine factors that improve local cardiac repair and endocrine-like effects to stimulate key stem-progenitor cells from their niches to further counter myocardial injury (Fig. 2). The most effective route of administration along with identification of the exact mechanisms of action of the trophic factors and exosomes remain to be uncovered in order to optimize clinical translation. Cardiac cellbased therapy, either via an invasive or remote manner, is indeed a promising adjuvant therapeutic strategy that can exploit advantageously the potency of the secretome of stem cells. 


\begin{abstract}
Abbreviations
AMI: Acute myocardial infarction; ASC: Adipose derived stem cell; ESC: Embryonic stem cell; EVs: Extracellular vesicles; FGF-2: Fibroblast growth factor 2; G/M-CSF: Granulocyte macrophage colony stimulating factor; HGF: Hepatocyte growth factor; ICM: Ischemic cardiomyopathy; IHD: Ischemic heart disease; IGF-1: Insulin growth factor 1; iPSC: Induced pluripotent stem cell; LIF: Leukemia inhibitory factor; LVEF: left ventricular ejection fraction; LVEDV: Left ventricular end-diastolic volume; MI: Myocardial infarction; miRNA: Micro RNA; MSC: Mesenchymal stem cell; NO: Nitric oxide; SDF1a: Stromal cell derived fac tor 1a; TGF- $\beta$ : Transforming growth factor B; TLR 3: Toll Like Receptor 3; VEGF: Vascular endothelial growth factor.
\end{abstract}

\section{Acknowledgements}

Not applicable.

\section{Authors' contributions}

CSO was responsible for conceptualization and manuscript writing. LPP and HQL performed final editing of the manuscript. All authors read and approved the final manuscript.

\section{Funding}

This work was supported by the Montreal Heart Institute Foundation, the ThéCell Network (Fond de Recherche du Québec-Santé FRQS), Chaire DesGroseillers-Bérard en Cardiologie Interventionnelle and Chaire Fondation Marcelle et Jean Coutu de traitements chirurgicaux novateurs en insuffisance cardiaque from Université de Montréal.

\section{Availability of data and materials}

Not applicable.

\section{Ethics approval and consent to participate}

Not applicable.

\section{Consent for publication}

Not applicable.

\section{Competing interests}

The authors declare that they have no competing interests.

\section{Author details}

1 Department of Pharmacology and Physiology, Université de Montréal, Montreal, QC, Canada. ${ }^{2}$ Department of Medicine, Université de Montréal, Montreal, QC, Canada. ${ }^{3}$ Research Centre, Montreal Heart Institute, Université de Montréal, 5000 Belanger Street, Montreal, QC H1T 1C8, Canada. ${ }^{4}$ Department of Cardiovascular Surgery, Montreal Heart Institute and Université de Montréal, Montreal, QC, Canada.

Received: 3 May 2020 Accepted: 26 August 2020

Published online: 01 September 2020

\section{References}

1. Roth GA, Johnson C, Abajobir A, Abd-Allah F, Abera SF, Abyu G, et al. Global, regional, and national burden of cardiovascular diseases for 10 causes, 1990 to 2015. J Am Coll Cardiol. 2017;70(1):1-25.

2. Wu R, Hu X, Wang J. Concise review: optimized strategies for stem cellbased therapy in myocardial repair: clinical translatability and potential limitation. Stem Cells. 2018;36(4):482-500.

3. Eschenhagen T, Bolli R, Braun T, Field LJ, Fleischmann BK, Frisen J, et al. Cardiomyocyte regeneration: a consensus statement. Circulation. 2017;136(7):680-6.

4. Bacakova L, Zarubova J, Travnickova M, Musilkova J, Pajorova J, Slepicka P, et al. Stem cells: their source, potency and use in regenerative therapies with focus on adipose-derived stem cells-a review. Biotechnol Adv. 2018;36(4):1111-26.

5. Dulak J, Szade K, Szade A, Nowak W, Jozkowicz A. Adult stem cells: hopes and hypes of regenerative medicine. Acta Biochim Pol. 2015;62(3):329-37.

6. Takahashi K, Yamanaka S. Induction of pluripotent stem cells from mouse embryonic and adult fibroblast cultures by defined factors. Cell. 2006;126(4):663-76
7. Shi Y, Inoue H, Wu JC, Yamanaka S. Induced pluripotent stem cell technology: a decade of progress. Nat Rev Drug Discov. 2017;16(2):115-30.

8. Girdlestone J. Mesenchymal stromal cells with enhanced therapeutic properties. Immunotherapy. 2016;8(12):1405-16.

9. Fraser JK, Wulur I, Alfonso Z, Hedrick MH. Fat tissue: an underappreciated source of stem cells for biotechnology. Trends Biotechnol. 2006:24(4):150-4

10. Shi Y, Wang Y, Li Q, Liu K, Hou J, Shao C, et al. Immunoregulatory mechanisms of mesenchymal stem and stromal cells in inflammatory diseases. Nat Rev Nephrol. 2018;14(8):493-507.

11. Bianco P. "Mesenchymal" stem cells. Annu Rev Cell Dev Biol. 2014;30:677-704

12. Iso Y, Spees JL, Serrano C, Bakondi B, Pochampally R, Song YH, et al. Multipotent human stromal cells improve cardiac function after myocardial infarction in mice without long-term engraftment. Biochem Biophys Res Commun. 2007;354(3):700-6

13. Ranganath $\mathrm{SH}$, Levy O, Inamdar MS, Karp JM. Harnessing the mesenchymal stem cell secretome for the treatment of cardiovascular disease. Cell Stem Cell. 2012;10(3):244-58.

14. Maltais S, Tremblay JP, Perrault LP, Ly HQ. The paracrine effect: pivotal mechanism in cell-based cardiac repair. J Cardiovasc Transl Res. 2010;3(6):652-62

15. Hare JM, Fishman JE, Gerstenblith G, DiFede Velazquez DL, Zambrano JP, Suncion VY, et al. Comparison of allogeneic vs autologous bone marrowderived mesenchymal stem cells delivered by transendocardial injection in patients with ischemic cardiomyopathy: the POSEIDON randomized trial. JAMA. 2012;308(22):2369-79.

16. Perin EC, Sanz-Ruiz R, Sanchez PL, Lasso J, Perez-Cano R, Alonso-Farto $\mathrm{JC}$, et al. Adipose-derived regenerative cells in patients with ischemic cardiomyopathy: the PRECISE trial. Am Heart J. 2014;168(1):88-95.e2.

17. Karantalis V, Hare JM. Use of mesenchymal stem cells for therapy of cardiac disease. Circ Res. 2015;116(8):1413-30.

18. Bagno L, Hatzistergos KE, Balkan W, Hare JM. Mesenchymal stem cellbased therapy for cardiovascular disease: progress and challenges. Mol Ther. 2018;26(7):1610-23.

19. Zuk PA, Zhu M, Mizuno H, Huang J, Futrell JW, Katz AJ, et al. Multilineage cells from human adipose tissue: implications for cell-based therapies. Tissue Eng. 2001;7(2):211-28.

20. Zuk P. Adipose-derived stem cells in tissue regeneration: a review. ISRN Stem Cells. 2013:2013:1-35.

21. Toyserkani NM, Jorgensen MG, Tabatabaeifar S, Jensen CH, Sheikh SP, Sorensen JA. Concise review: a safety assessment of adipose-derived cell therapy in clinical trials: a systematic review of reported adverse events. Stem Cells Transl Med. 2017;6(9):1786-94.

22. Planat-Benard V, Silvestre JS, Cousin B, Andre M, Nibbelink M, Tamarat $\mathrm{R}$, et al. Plasticity of human adipose lineage cells toward endothelial cells: physiological and therapeutic perspectives. Circulation. 2004;109(5):656-63.

23. Rangappa S, Fen C, Lee EH, Bongso A, Sim EK. Transformation of adult mesenchymal stem cells isolated from the fatty tissue into cardiomyocytes. Ann Thorac Surg. 2003;75(3):775-9.

24. Lee WC, Sepulveda JL, Rubin JP, Marra KG. Cardiomyogenic differentiation potential of human adipose precursor cells. Int J Cardiol. 2009;133(3):399-401.

25. Wang $H$, Shi J, Wang Y, Yin Y, Wang L, Liu J, et al. Promotion of cardiac differentiation of brown adipose derived stem cells by chitosan hydrogel for repair after myocardial infarction. Biomaterials. 2014;35(13):3986-98.

26. Rigol M, Solanes N, Roura S, Roque M, Novensa L, Dantas AP, et al. Allogeneic adipose stem cell therapy in acute myocardial infarction. Eur J Clin Invest. 2014:44(1):83-92.

27. Yoon YS, Wecker A, Heyd L, Park JS, Tkebuchava T, Kusano K, et al. Clonally expanded novel multipotent stem cells from human bone marrow regenerate myocardium after myocardial infarction. J Clin Invest. 2005;115(2):326-38

28. Valina C, Pinkernell K, Song YH, Bai X, Sadat S, Campeau RJ, et al. Intracoronary administration of autologous adipose tissue-derived stem cells improves left ventricular function, perfusion, and remodelling after acute myocardial infarction. Eur Heart J. 2007;28(21):2667-77.

29. Acquistapace A, Bru T, Lesault PF, Figeac F, Coudert AE, le Coz O, et al. Human mesenchymal stem cells reprogram adult cardiomyocytes 
toward a progenitor-like state through partial cell fusion and mitochondria transfer. Stem Cells. 2011;29(5):812-24.

30. Bai X, Yan Y, Song YH, Seidensticker M, Rabinovich B, Metzele R, et al. Both cultured and freshly isolated adipose tissue-derived stem cells enhance cardiac function after acute myocardial infarction. Eur Heart J. 2010;31(4):489-501.

31. Otto Beitnes J, Oie E, Shahdadfar A, Karlsen T, Muller RM, Aakhus S, et al. Intramyocardial injections of human mesenchymal stem cells following acute myocardial infarction modulate scar formation and improve left ventricular function. Cell Transplant. 2012;21 (8):1697-709.

32. Duque G, Huang DC, Macoritto M, Rivas D, Yang XF, Ste-Marie LG, et al. Autocrine regulation of interferon gamma in mesenchymal stem cells plays a role in early osteoblastogenesis. Stem Cells. 2009:27(3):550-8.

33. Rider DA, Dombrowski C, Sawyer AA, Ng GH, Leong D, Hutmacher DW, et al. Autocrine fibroblast growth factor 2 increases the multipotentiality of human adipose-derived mesenchymal stem cells. Stem Cells. 2008;26(6):1598-608.

34. Hamidouche Z, Fromique $O$, Nuber $U$, Vaudin $P$, Pages JC, Ebert $R$, et al. Autocrine fibroblast growth factor 18 mediates dexamethasone-induced osteogenic differentiation of murine mesenchymal stem cells. J Cell Physiol. 2010;224(2):509-15.

35. Hemmingsen M, Vedel S, Skafte-Pedersen P, Sabourin D, Collas P, Bruus $\mathrm{H}$, et al. The role of paracrine and autocrine signaling in the early phase of adipogenic differentiation of adipose-derived stem cells. PLoS ONE. 2013;8(5):e63638.

36. Mayer $\mathrm{H}$, Bertram $\mathrm{H}$, Lindenmaier W, KorffT, Weber $\mathrm{H}$, Weich $\mathrm{H}$. Vascular endothelial growth factor (VEGF-A) expression in human mesenchymal stem cells: autocrine and paracrine role on osteoblastic and endothelial differentiation. J Cell Biochem. 2005;95(4):827-39.

37. Eom YW, Oh JE, Lee Jl, Baik SK, Rhee KJ, Shin HC, et al. The role of growth factors in maintenance of stemness in bone marrow-derived mesenchymal stem cells. Biochem Biophys Res Commun. 2014;445(1):16-22.

38. Dumitru CA, Hemeda H, Jakob M, Lang S, Brandau S. Stimulation of mesenchymal stromal cells (MSCS) via TLR3 reveals a novel mechanism of autocrine priming. FASEB J. 2014;28(9):3856-66.

39. Lee BC, Kim HS, Shin TH, Kang I, Lee JY, Kim JJ, et al. PGE2 maintains self-renewal of human adult stem cells via EP2-mediated autocrine signaling and its production is regulated by cell-to-cell contact. Sci Rep. 2016;6:26298.

40. Nakagami H, Maeda K, Morishita R, Iguchi S, Nishikawa T, Takami Y, et al. Novel autologous cell therapy in ischemic limb disease through growth factor secretion by cultured adipose tissue-derived stromal cells. Arterioscler Thromb Vasc Biol. 2005;25(12):2542-7.

41. Sadat S, Gehmert S, Song YH, Yen Y, Bai X, Gaiser S, et al. The cardioprotective effect of mesenchymal stem cells is mediated by IGF-I and VEGF. Biochem Biophys Res Commun. 2007;363(3):674-9.

42. Lee RH, Pulin AA, Seo MJ, Kota DJ, Ylostalo J, Larson BL, et al. Intravenous hMSCs improve myocardial infarction in mice because cells embolized in lung are activated to secrete the anti-inflammatory protein TSG-6. Cell Stem Cell. 2009;5(1):54-63.

43. Bobi J, Solanes N, Fernandez-Jimenez R, Galan-Arriola C, Dantas AP, Fernandez-Friera $\mathrm{L}$, et al. Intracoronary administration of allogeneic adipose tissue-derived mesenchymal stem cells improves myocardial perfusion but not left ventricle function, in a translational model of acute myocardial infarction. J Am Heart Assoc. 2017;6(5):e005771.

44. Wang X, Xi WC, Wang F. The beneficial effects of intracoronary autologous bone marrow stem cell transfer as an adjunct to percutaneous coronary intervention in patients with acute myocardial infarction. Biotechnol Lett. 2014;36(11):2163-8.

45. Chen SL, Fang WW, Ye F, Liu YH, Qian J, Shan SJ, et al. Effect on left ventricular function of intracoronary transplantation of autologous bone marrow mesenchymal stem cell in patients with acute myocardial infarction. Am J Cardiol. 2004;94(1):92-5.

46. Gao LR, Pei XT, Ding QA, Chen Y, Zhang NK, Chen HY, et al. A critical challenge: dosage-related efficacy and acute complication intracoronary injection of autologous bone marrow mesenchymal stem cells in acute myocardial infarction. Int J Cardiol. 2013;168(4):3191-9.

47. Makkar RR, Smith RR, Cheng K, Malliaras K, Thomson LE, Berman D, et al. Intracoronary cardiosphere-derived cells for heart regeneration after myocardial infarction (CADUCEUS): a prospective, randomised phase 1 trial. Lancet. 2012;379(9819):895-904.
48. Mu D, Zhang XL, Xie J, Yuan HH, Wang K, Huang W, et al. Intracoronary transplantation of mesenchymal stem cells with overexpressed integrinlinked kinase improves cardiac function in porcine myocardial infarction. Sci Rep. 2016;6:19155.

49. Perin EC, Silva GV, Assad JA, Vela D, Buja LM, Sousa AL, et al. Comparison of intracoronary and transendocardial delivery of allogeneic mesenchymal cells in a canine model of acute myocardial infarction. J Mol Cell Cardiol. 2008:44(3):486-95.

50. Yang $D$, Wang W, Li L, Peng $Y$, Chen $P$, Huang $H$, et al. The relative contribution of paracine effect versus direct differentiation on adiposederived stem cell transplantation mediated cardiac repair. PLoS ONE. 2013;8(3):e59020.

51. Mendt M, Rezvani K, Shpall E. Mesenchymal stem cell-derived exosomes for clinical use. Bone Marrow Transplant. 2019;54(Suppl 2):789-92.

52. Bian S, Zhang L, Duan L, Wang X, Min Y, Yu H. Extracellular vesicles derived from human bone marrow mesenchymal stem cells promote angiogenesis in a rat myocardial infarction model. J Mol Med. 2014;92(4):387-97.

53. Teng $X$, Chen $L$, Chen W, Yang J, Yang Z, Shen Z. Mesenchymal stem cell-derived exosomes improve the microenvironment of infarcted myocardium contributing to angiogenesis and anti-inflammation. Cell Physiol Biochem. 2015;37(6):2415-24.

54. Katsuda T, Tsuchiya R, Kosaka N, Yoshioka Y, Takagaki K, Oki K, et al. Human adipose tissue-derived mesenchymal stem cells secrete functional neprilysin-bound exosomes. Sci Rep. 2013;3:1197.

55. Lopez-Verrilli MA, Caviedes A, Cabrera A, Sandoval S, Wyneken U, Khoury M. Mesenchymal stem cell-derived exosomes from different sources selectively promote neuritic outgrowth. Neuroscience. 2016;320:129-39.

56. Nakanishi C, Yamagishi M, Yamahara K, Hagino I, Mori H, Sawa Y, et al. Activation of cardiac progenitor cells through paracrine effects of mesenchymal stem cells. Biochem Biophys Res Commun. 2008;374(1):11-6.

57. Wang QL, Wang HJ, Li Z H, Wang YL, Wu XP, Tan YZ. Mesenchymal stem cell-loaded cardiac patch promotes epicardial activation and repair of the infarcted myocardium. J Cell Mol Med. 2017;21(9):1751-66.

58. Karp JM, Leng Teo GS. Mesenchymal stem cell homing: the devil is in the details. Cell Stem Cell. 2009;4(3):206-16.

59. Mao C, Hou X, Wang B, Chi J, Jiang Y, Zhang C, et al. Intramuscular injection of human umbilical cord-derived mesenchymal stem cells improves cardiac function in dilated cardiomyopathy rats. Stem Cell Res Ther. 2017:8(1):18.

60. Shabbir A, Zisa D, Suzuki G, Lee T. Heart failure therapy mediated by the trophic activities of bone marrow mesenchymal stem cells: a noninvasive therapeutic regimen. Am J Physiol Heart Circ Physiol. 2009;296(6):H1888-97.

61. Preda MB, Ronningen T, Burlacu A, Simionescu M, Moskaug JO, Valen G. Remote transplantation of mesenchymal stem cells protects the heart against ischemia-reperfusion injury. Stem Cells. 2014;32(8):2123-34.

62. Wang W, Chen N, Shen X, Cunningham P, Fauty S, Michel K, et al. Lymphatic transport and catabolism of therapeutic proteins after subcutaneous administration to rats and dogs. Drug Metab Dispos. 2012;40(5):952-62.

63. Sheng $H$, Wang $Y$, Jin $Y$, Zhang $Q$, Zhang $Y$, Wang $L$, et al. A critical role of IFNgamma in priming MSC-mediated suppression of T cell proliferation through up-regulation of B7-H1. Cell Res. 2008;18(8):846-57.

64. Chen CW, Okada M, Proto JD, Gao X, Sekiya N, Beckman SA, et al. Human pericytes for ischemic heart repair. Stem Cells. 2013;31 (2):305-16.

65. Kennedy-Lydon T. Immune functions and properties of resident cells in the heart and cardiovascular system: pericytes. Adv Exp Med Biol. 2017;1003:93-103.

66. Houtgraaf $J \mathrm{H}$, den Dekker WK, van Dalen BM, Springeling T, de Jong R, van Geuns RJ, et al. First experience in humans using adipose tissuederived regenerative cells in the treatment of patients with ST-segment elevation myocardial infarction. J Am Coll Cardiol. 2012;59(5):539-40.

67. Bartunek J, Behfar A, Dolatabadi D, Vanderheyden M, Ostojic M, Dens J, et al. Cardiopoietic stem cell therapy in heart failure: the C-CURE (Cardiopoietic stem Cell therapy in heart failURE) multicenter randomized trial with lineage-specified biologics. J Am Coll Cardiol. 2013;61(23):2329-38.

68. Karantalis V, DiFede DL, Gerstenblith G, Pham S, Symes J, Zambrano JP, et al. Autologous mesenchymal stem cells produce concordant improvements in regional function, tissue perfusion, and fibrotic burden when administered to patients undergoing coronary artery bypass grafting: the Prospective Randomized Study of Mesenchymal Stem Cell Therapy 
in Patients Undergoing Cardiac Surgery (PROMETHEUS) trial. Circ Res. 2014;114(8):1302-10.

69. Gao LR, Chen Y, Zhang NK, Yang XL, Liu HL, Wang ZG, et al. Intracoronary infusion of Wharton's jelly-derived mesenchymal stem cells in acute myocardial infarction: double-blind, randomized controlled trial. BMC Med. 2015;13:162.

70. Florea V, Rieger AC, DiFede DL, El-Khorazaty J, Natsumeda M, Banerjee $\mathrm{MN}$, et al. Dose comparison study of allogeneic mesenchymal stem cells in patients with ischemic cardiomyopathy (The TRIDENT Study). Circ Res. 2017;121(11):1279-90.

71. Bartunek J, Terzic A, Davison BA, Filippatos GS, Radovanovic S, Beleslin $B$, et al. Cardiopoietic cell therapy for advanced ischaemic heart failure: results at 39 weeks of the prospective, randomized, double blind, shamcontrolled CHART-1 clinical trial. Eur Heart J. 2017;38(9):648-60.
72. Henry TD, Pepine CJ, Lambert CR, Traverse JH, Schatz R, Costa M, et al. The Athena trials: autologous adipose-derived regenerative cells for refractory chronic myocardial ischemia with left ventricular dysfunction. Catheter Cardiovasc Interv. 2017;89(2):169-77.

73. Qayyum AA, Mathiasen AB, Mygind ND, Kuhl JT, Jorgensen E, Helqvist S, et al. Adipose-derived stromal cells for treatment of patients with chronic ischemic heart disease (MyStromalCell Trial): a randomized placebocontrolled study. Stem Cells Int. 2017;2017:5237063.

\section{Publisher's Note}

Springer Nature remains neutral with regard to jurisdictional claims in published maps and institutional affiliations.
Ready to submit your research? Choose BMC and benefit from:

- fast, convenient online submission

- thorough peer review by experienced researchers in your field

- rapid publication on acceptance

- support for research data, including large and complex data types

- gold Open Access which fosters wider collaboration and increased citations

- maximum visibility for your research: over $100 \mathrm{M}$ website views per year

At BMC, research is always in progress.

Learn more biomedcentral.com/submissions 